\title{
EVALUATION OF MODIFIED KNITWEAR PROPERTIES
}

\author{
Ieva Bake, Vineta Afanasjeva, Silvija Kukle \\ Riga Technical University, Latvia \\ ieva.bake@edu.rtu.lv
}

\begin{abstract}
Textile functionality can be complimented using nano-scale coatings, integrating electro conductive yarns, sensors and electronic systems. Therefore, integration of electroconductive materials in products needs a special care, because they are easily damaged by hydrothermal treatments. As concluded in the previous studies, the sol gel technique is effective for the modification of textiles. The focus of this study is to modify pure cotton yarns before the complicated electroconductive systems are integrated into knitwear. The modification of textile materials with silica-based sol and zinc acetate dihydrate as the modifier can provide new properties, such as self-cleaning, antibacterial and UV - protection simultaneously improving particular mechanical properties like tensile strength and resistance to abrasion. However, it is important that the modification does not negatively affect the wear comfort properties of the final product. Therefore, air and water vapour permeability had to be tested as a significant indicator of wear comfort. The final samples are produced by blending modified or unmodified cotton yarns $(75 \mathrm{wt} \%)$ with polyamide $(21 \mathrm{wt} \%)$ and elastane $(5 \mathrm{wt} \%)$ and knitting a plainwovenknitwear. For that four hanks of cotton yarns were modified in a silica-based sol, with $7.5 \mathrm{wt} \%$ zinc acetate dehydrate integrated as a modifier; following an after-treatment consolidation for 5 minutes at $120^{\circ} \mathrm{C}$. As the nanoscale coating merges with the modified surface, the linear density of the fabric increases, resulting in the decrease of air permeability. In this case the average air permeability of the samples containing modified yarn decreases by $20 \%$, comparing to the ones with unmodified. A slight decrease $(3 \%)$ was observed for water vapour permeability. Such decrease is considered as not critical to significantly affect the comfort properties. Wear resistance tests of the obtained knitwear, using a non-oriented (randomly across the surface) friction testing method, show significant surface defects for the unmodified samples after $5 \cdot 10^{3}$ friction cycles, whereas for the modified samples - after $1.5 \cdot 10^{4}$ to $2 \cdot 10^{4}$ friction cycles.
\end{abstract}

Keywords: cotton yarns, sol-gel technique, nano-coatings, thermo-physical comfort.

\section{Introduction}

Application of silicon based nano-coatings on electroconductive yarns has been proven effective in prolonging conductivity after washing[1]. This study aims to complement the previous research and expand modification options for smart textile products. Sol-gel technique was chosen for modification, since it allows improvements on such mechanical properties as the yarn tensile strength and wear resistance. However, it was decided to modify cotton yarns separately before knitting a smart sock prototype with embedded stance correction sensors in order to avoid possible sensor damage during the modification process.

Due to the wide surface area and ability to retain moisture, textile structure, especially, knitwear is known to be particularly susceptible to microorganisms, bacteria and fungi, which are widely found in human skin micro flora. Taking into account that socks are first base layer clothing- moisture, temperature and nutrient abundance are the main factors leading to increase of bacteria growth[2]. Previous studies have proven the surface coatings obtained by sol-gel method to be effective against bacteria that can cause destruction of cellulose and are present in human sweat as well as against some fungus causing typical skin infections [3]. Moreover, the chosen technique can prolong time period in between washes, which is important, since electroconductive yarns and sensors gradually lose their properties during the washing process.

Zinc has excellent antibacterial properties, and by integrating $\mathrm{Zn}$ nanoparticles in the sol gel system, it is possible via nanocoating to give textile antibacterial qualities [2]. The aim of this study is to incorporate modified yarns into a smart sock prototype with integrated sensors for stance correction. The chosen modification must ensure sufficient air and water vapour permeability as well improve the yarn tensile strength and wear resistance.

\section{Materials and methods}

For sol synthesis silica based alkoxide thetraetilortosilicate $\mathrm{C}_{8} \mathrm{H}_{20} \mathrm{O}_{4} \mathrm{Si}$ (TEOS)was used. Ethanol $\left(\mathrm{C}_{2} \mathrm{H}_{5} \mathrm{OH}\right)$ and distilled water $\left(\mathrm{H}_{2} \mathrm{O}\right)$ are added for hydrolysis and condensation of alkoxide. Hydrofluoric acid (HF) with purity of $\geq 40$ is used as a catalysator.7.5 wt \% Zinc acetate dehydrate $\left(\mathrm{Zn}\left(\mathrm{CH}_{3} \mathrm{COO}\right)_{2} \cdot 2 \mathrm{H}_{2} \mathrm{O}\right)$ is integrated into the sol system and used as a modifier. Sol preparation and 
coatingadhesion with cotton were discussed in the previous studies and researches [3;4]. The $2^{2}$ factorial design was applied to the four hanks of black pure cotton yarns (24 tex) with the mean weight of $100 \mathrm{~g}$ to analyse the sol synthesis parameters influence on the coating quality (stirring time, temperature, $\mathrm{pH}$ ) as well as the solution ratios of $1: 8$ and $1: 12 \mathrm{~g} \cdot \mathrm{ml}^{-1}$ and the dipping time of 5 and 15 minutes were variables in this experiment with subsequent consolidation within 5 minutes at $120^{\circ} \mathrm{C}$ for all samples. All solutions are stirred separately and then divided for each sample group.

Modified and control cotton yarns were reeled up on cones to prepare for processing on the knitting machine. Cotton $(75 \mathrm{wt} \%)$ yarns were combined with polyamide (21 wt \%) and elastane (4 wt \%) yarns and knitted in plain woven knitted fabrics with the total density of the control sample $144 \mathrm{~g} \cdot \mathrm{cm}^{-3}$ and average of $147 \mathrm{~g} \cdot \mathrm{cm}^{-3}$ for the modified samples.

Modified and unmodified knitwear samples were subjected to the hydrothermal treatment according to the EN ISO 105C10-A01:2007 standard [5]: washing at $40{ }^{\circ} \mathrm{C}$ for 30 minutes with a phosphate- free detergent and without optical brighteners $\left(5 \mathrm{~g} \cdot 1^{-1}\right)$. Samples were hand washed and twice rinsed with distilled water and dried under normal climatic conditions $\left(20 \pm 2{ }^{\circ} \mathrm{C}\right.$, relative humidity $65 \pm 2 \%$ ). Before the tests all samples were stored in the climate chamber "Binder KBF $115 "$ according to the ISO 139:2005 standard in normal climate conditions [6].

Air permeability of cloth characterizes the air flow that can pass through textile, this property also affects the textile final application. Air permeability is determined by the amount of air passing through the material in a specific amount of time and the pressure difference on both sides of the material [7]. Air permeability was tested using the"SDL Atlas Air Permeability"tester according to the LVS EN ISO 9237:2001 standard. Used sample test area was $5 \mathrm{~cm}^{2}$, the selected air pressure difference on both sides of the material was $100 \mathrm{~Pa}$. For each sample 10 measurements were made in different places. Average air permeability is expressed $\mathrm{dm}^{3} \cdot \mathrm{min}^{-1}$ or $1 \cdot \mathrm{min}^{-1}$. Coefficient of air permeability (R) is expressed $\mathrm{mm} \cdot \mathrm{s}^{-1}$ and can be converted to $\mathrm{dm}^{3} \cdot \mathrm{min}^{-1}$ or $1 \cdot \mathrm{min}^{-1}$ to $\mathrm{mm} \cdot \mathrm{s}^{-1}$, with anequation, where the average air permeability is divided by the tested area of the sample and multiplied with 167 - the numerical value for converting values $\left(\mathrm{dm}^{3} \cdot \mathrm{min}^{-1}\right.$ or $1 \cdot \mathrm{min}^{-1}$ to $\left.\mathrm{mm} \cdot \mathrm{s}^{-1}\right)$ [7] .

Water vapour permeability is an important indicator of thermophysical comfort. Modification and testing are done with the idea that the end product will be a sock and water vapour permeability is one of the factors that can affect the users' comfort level. Modified and control samples were tested using the "Permetest. Skin model" according to the EN ISO 11092:2014 standard [8]. Before using the equipment is calibrated with certified textiles. The resulting calibration factor is used to calculate mean values of measurements. Sample testing area is $\varnothing 80 \mathrm{~mm}$, minimum size of the samples is $12 \mathrm{~cm}^{2}$. Calibration coefficient for this test was 0.88 .

Friction is the main cause of textile material wear damage. During friction the fibre structure is damaged and bounds between yarns are loosened. The abrasion or wear resistance in this research is characterized by the number of friction cycles to complete material collapse. Test sample area with size of $\varnothing 38 \mathrm{~mm}$ was placed into a holder with the wearable side down. Abrasive wool worsted fabric is used for testing. Samples are pressured with the load $595 \pm 7 \mathrm{~g}$, corresponding with nominal $9 \mathrm{kPa}$, which is close to the pressure that the fabrics would face under realistic conditions."SDL Atlas M235 Martindale"tester was used according to the ISO 12947-1:1998 standard [9]. Samples were subjected to non-oriented chaotic friction across the surface.

Yarn tensile strength has the main quality indicator was determined using the "Instron 3300" universal testing system and Instron Bulehill Lite Material Testing software. All samples were tested with previous tension $12 \mathrm{cN}\left(0.5 \pm 0.1 \mathrm{cN} \cdot \mathrm{tex}^{-1}\right)$ that was applied according to the yarn linear density 24 tex and sample length between testing clamps $500 \mathrm{~mm}$ and extension rate $500 \mathrm{~mm} \cdot \mathrm{min}^{-1}$ according to the LVS EN ISO 2062:2010 standard [10]. 100 measurements for each sample were tested.

\section{Results and discussion}

Textile air permeability depends on the parameters, like textile porosity, structure, textile and yarn density [11] - modified samples had shown increase in the density by $2.6 \%$, which naturally decreases air permeability. After the yarn modification the air permeability decreases in average by $20.6 \%$, the unmodified knitwear shows the air permeability of $518.19 \mathrm{~mm} \cdot \mathrm{s}^{-1}$ (Fig.1, point K). The 
highest air permeability of the modified samples was observed in the sample D $432.5 \mathrm{~mm} \cdot \mathrm{s}^{-1}$ and the lowest at $394.2 \mathrm{~mm} \cdot \mathrm{s}^{-1}$. The coloration of yarn, linear density and air permeability can be described with polynomial relation with equation (1).

$$
Y_{a p}=12.303 x_{T}^{2}-660.17 x_{T}+9244.7, R^{2}=0.906,
$$

where $Y_{a p}$-air permeability, $\mathrm{mm} \cdot \mathrm{s}^{-1}$;

$x_{T}$ - linear density of yarn, tex;

$R^{2}$ - determination coefficient.

After washing the surface consolidation process takes place, where the coating gradually merges with the modified surface, therefore, increasing the yarn structure and texture changes, which can be observed in the air permeability tests. Shown groups of measurements on the curve are average of 10 measurements.

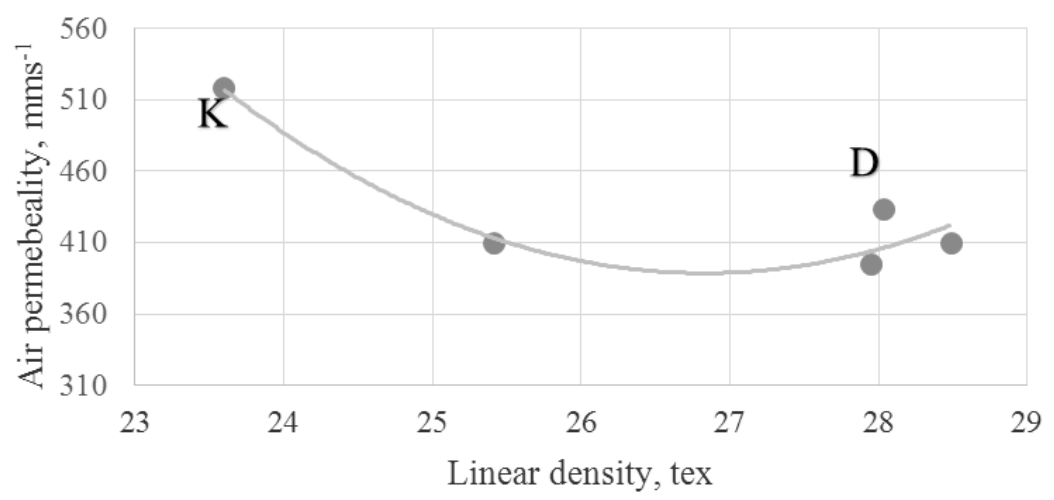

Fig.1. Variation in air permeability of knitted samples depending on cotton yarn linear density

Water vapour permeability mechanism and speed are affected by the textile structure and density. However, there are separate textile groups that are waterproof, but permeable, vapour permeability mechanisms are based on the diffusion process. Water vapour permeability test is done in order to observe how the applied coatings influence the modified samples. After the yarn modification the water vapour permeability decreases by $3 \%$ for the modified samples. Average value of unmodified knitwear was $3.60 \mathrm{~m}^{2} \mathrm{~Pa} \cdot \mathrm{W}^{-1}$. Standard error of water vapor permeability measurements varies in a range from 0.25 to $3.91 \%$ and decreases substantially after sol gel treatment. Increased linear density of yarns has an effect on the obtained knitwear average vapour permeability and is described with polynomial equation (2). Fig.3. shows average measurements of the modified samples.

$$
Y_{v p}=-0.095{x_{T}}^{2}+5.288 x_{T}+70.123, R^{2}=0.990,
$$

Where $\quad Y_{v p}$-vapour permeability, $\mathrm{m}^{2} \mathrm{~Pa} \cdot \mathrm{W}^{-1}$;

$x_{T}$ - linear density of yarn, tex;

$R^{2}$ - determination coefficient.

Wear resistance of a fabric depends on various characteristics of its structure, like the chemical composition, linear density, structure and the length of fibre, twist of the yarn, material surface density and surface finishings. In the previous studies sol gel finishes on cotton have showed abrasion resistance [3]. Visual defects (fabric fluffing) of the unmodified samples can be detected after $1 \cdot 10^{3}$ friction cycles, after 100 cycles coloration of abrasive material is observed. Defects of the modified samples are observed after $5 \cdot 10^{3}$ friction cycles, and colour fastness of the modified samples is higher and abrasive material staining is observed after $1 \cdot 10^{3}$ friction cycles. Defects as pilling of fabrics occur when fibres are broken and separated from yarns [12]. For the control sample the pilling defect occurred after $5 \cdot 10^{3}$ friction cycles and for the modified samples $1.5 \cdot 10^{4}$ to $2 \cdot 10^{4}$ indicating reduction of coating on the surface. Comparative photo fixation is shown in Fig. 3. 


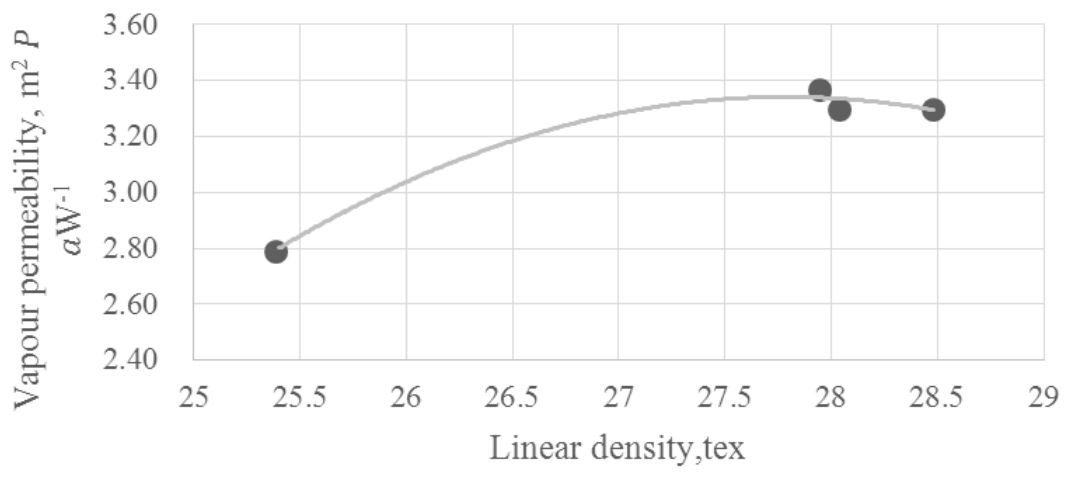

Fig. 2. Variation in water vapour permeability of knitted samples depending on cotton yarn linear density

After $4 \cdot 10^{4}$ testing cycles the control and modified samples look similarly worn with damaged cotton fibres, indicating the reduction of coating after $1.5 \cdot 10^{4}$ for sample $\mathrm{B}$ and $2 \cdot 10^{4}$ friction cycles for sample $\mathrm{C}$. The obtained results show that the surface treatment with silica-based sol modified with zinc acetate dehydrate improves wear resistance as well as reduces the pilling effect of fabric, which ensures longer aesthetic look of the product and prolongs the product life cycle, which is important for sock products that are exposed to higher loads and wear abrasion.
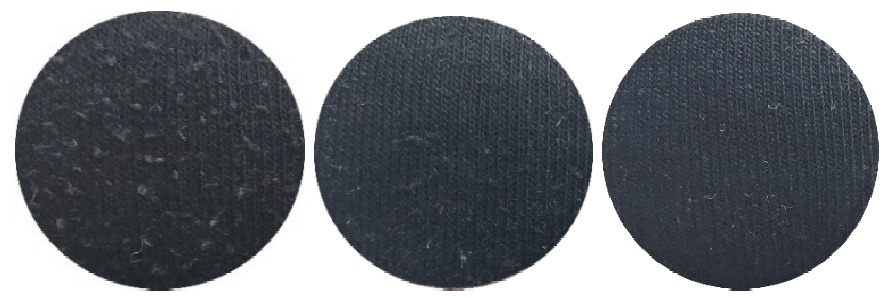

$5 \cdot 10^{3}$ friction cycles
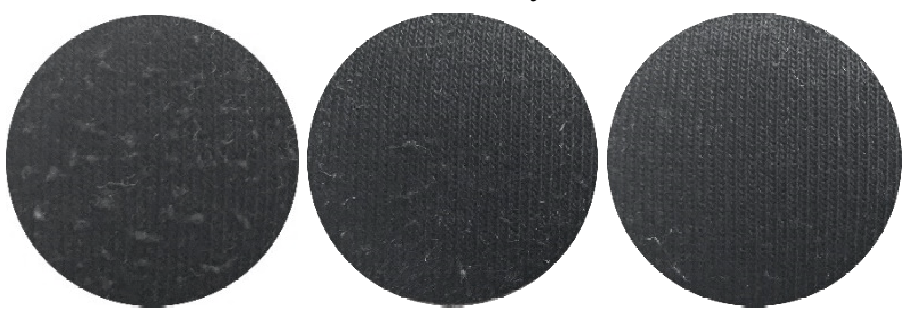

$1.5 \cdot 10^{4}$ friction cycles
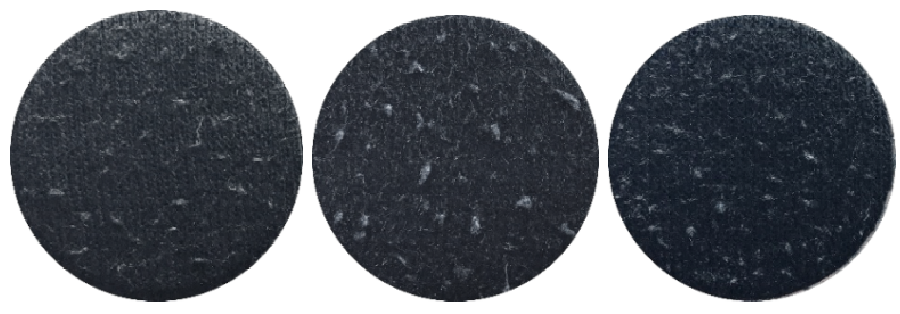

$4 \cdot 10^{4}$ frictioncycles

a)

b)

c)

Fig. 3. Fabric photo fixation after $5 \cdot 10^{3}, 1.5 \cdot 10^{4}$ and $4 \cdot 10^{4}$ friction cycles: a - control sample; $\mathrm{b}$ - modified sample A; $\mathrm{c}$ - modified sample $\mathrm{C}$

Ongoing study on cotton yarn modification followed the $2^{2}$ factorial design experiment, where the independent variables were $x_{s r}\left(8\right.$ and $\left.12 \mathrm{~g} \cdot \mathrm{ml}^{-1}\right)$ and $x_{d t}(5$ and 15 minutes). Effects of modification on the tensile stress at maximum load were analysed as part of the yarn tensile strength research. Average maximum load at the breaking point for the control samples is $229.91 \mathrm{cN}$ and after modification the values increase by $29 \%$. 
The equation (3) in form of incomplete second-degree polynomial shows quantitative influence of the factors under investigation and their mutual interactions on yarn tensile stress at maximum load.

$$
Y_{t s}=307.72+8.129 x_{s r}-6.32 x_{d t}+14.524 x_{s r} x_{d t}
$$

where $Y_{t s}-$ tensile stress at maximum load, $\mathrm{K} \cdot \mathrm{Pa}^{-1}$;

$x_{s r}$ - solution ratio to sample, $\mathrm{K} \cdot \mathrm{Pa}^{-1}$;

$x_{d t}-$ dipping time, min.
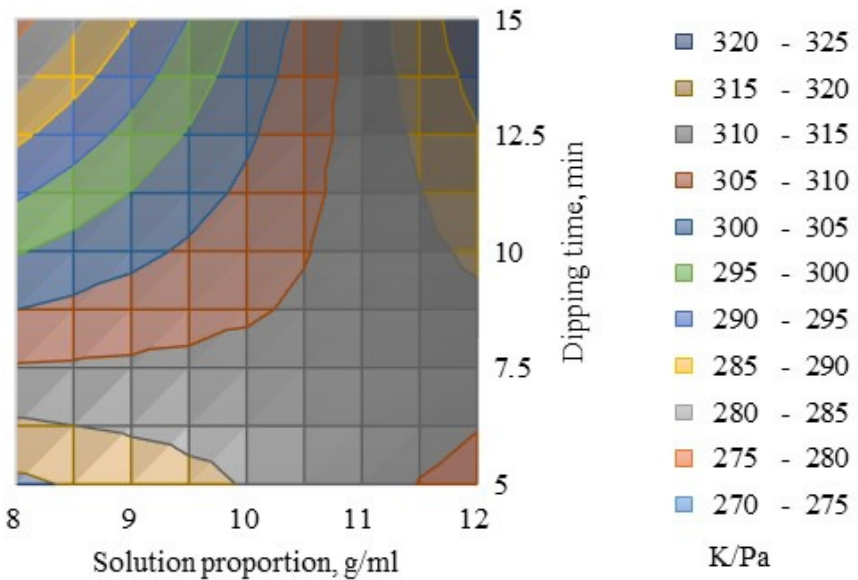

Fig. 4. Contour plot of response surface of yarn tensile stress at max. load of modified samples

Coefficient of $x_{s r}$ shows that the sample dipping time has more influence on the results, as well mutual interaction of both variables is more important. Contour plot of response surface shown in Fig. 4 allows to better analyse the comparative nature of variable parameters. Higher tensile stress at maximum load indicates the amount of force that the tested material can withstand before elongation and breaking point.

The graphic shows that the highest values of $320-325 \mathrm{~K} \cdot \mathrm{Pa}^{-1}$, can be achieved using 12 solution ratio and the dipping time for 15 minutes, thereforelower ratio and higher dipping time shows the values of $280-275 \mathrm{~K} \cdot \mathrm{Pa}^{-1}$. Optimal results can bet achieved without solution proportion 10 and the dipping time to 5-6 min with the values of $315-320 \mathrm{~K} \cdot \mathrm{Pa}^{-1}$.

Further investigations continue and testing of antibacterial activity against gram positive organisms Staphylococcus aureus and Bacillus subtilis of modified samples is in progress as well as investigation of the yarn and knitwear properties after modification.

\section{Conclusions}

Sol gel technique can be applied to cotton yarn modification and later production into knitwear, during this study the following conclusions are made:

1. Air and water vapour permeability decrease by $20.6 \%$ and $3 \%$ after modification and following washing due to coatings fusion with the surface and increasing the linear density.

2. It must be taken into consideration that increasing the yarn linear density will increase the knitwear overall density, when these yarns are combined with unmodified polyamide and elastane threads.

3. The applied modification bonds the fibre surface thus increasing the fabrics' resistance to abrasion. Functional coating coverage on the surface is damaged after $1.5 \cdot 10^{4}$ to $2 \cdot 10^{4}$ friction cycles.

4. Higher solution ratio - 1:12 and the dipping time of 15 min show higher results on the yarn tensile strength. After modification the tensile strength of yarns increases, showing the average values of $322.56 \mathrm{cN}$.

\section{Acknowledgements}

The authors gratefully acknowledge the funding by the Riga Technical university grant, Latvia, PVS ID 3926. 


\section{References}

[1] Sahta I., Baltina I., Truskovska N., Blums J., Deksnis, E. Selection of Conductive Yarns for Knitting an Electrical Heating Element. High Performance and Optimum Design of Structures and Materials. UK: WIT Press, 2014. pp.91-102.

[2] Morais D.S., Guedes R.M., Lopes M.A. Review: Antimicrobial Approaches for Textiles: From Research to Market. Materials, vol.9(6), 2016, pp.498.

[3] Vihodceva S. Nanolīmenī modificētu tekstiliju sortimenta paplašināšana(Extension of the range of textiles modified at nanolevel)Doctoral Thesis. Riga: RTU Izdevniecība. 2014. 207 p. (In Latvian).

[4] Kukle S., Vihodceva S., Belakova D., Lukasevica B., Riepniece A. At the Nano-level Modified Cotton Knitwear Prototype Development. IOP Conference Series: Materials Science and Engineering, 2017, Vol.254, Iss.12: Surface Functionalization and Coating, pp.122005-1-1220055 .

[5] ISO 105C10-A01:2007 standard "Textiles - Tests for colour fastness - Part A01: General principles of testing".

[6] ISO 139:2005 standard "Textiles.Standard atmospheres for conditioning and testing".

[7] Baltina I. Metodiskie norādījumi laboratorijas darbiem tekstilmateriālzinībās (Methodical guidelines for laboratory work in textilematerialscience), Rīga: RTU Izdevniecība, 2007.43 p. ( In Latvian).

[8] EN ISO 11092:2014 standard "TextilesPhysiological effects: Measurement of thermal and watervapour resistance under steady-state conditions (sweating guarded-hotplate test)".

[9] ISO 12947-1:1998 standard "Textiles -- Determination of the abrasion resistance of fabrics by the Martindale method -- Part 1: Martindale abrasion testing apparatus".

[10]LVS EN ISO 2062:2010 standard "Textiles -- Yarns from packages -- Determination of singleend breaking force and elongation at break using constant rate of extension (CRE) tester".

[11] Bhattacharya S. S., Ajmeri J., R. Factors Affecting Air Permeability of Viscose \& Excel Single Jersey Fabric. International Journal of Engineering Research and Development, vol. 5(7), 2013, pp. 48-54.

[12] Textile Innovation Knowledge Platform "Pill Resistance" [online] [19.03.2019]. Available at: http://www.tikp.co.uk/knowledge/material-functionality/pill-resistance/. 